\title{
How Today's Consumers Perceive Tomorrow's Smart Products*
}

\author{
Serge A. Rijsdijk and Erik Jan Hultink
}

This paper investigates consumer responses to new smart products. Due to the application of information technology, smart products are able to collect, process, and produce information and can be described as "thinking" for themselves. In this study, 184 consumers respond to smart products that are characterized by two different combinations of smartness dimensions. One group of products shows the smartness dimensions of autonomy, adaptability, and reactivity. Another group of smart products are multifunctional and able to cooperate with other products. Consumer responses to these smart products are measured in terms of the innovation attributes of relative advantage, compatibility, observability, complexity, and perceived risk. The study shows that products with higher levels of smartness are perceived to have both advantages and disadvantages. Higher levels of product smartness are mainly associated with higher levels of observability and perceived risk. The effects of product smartness on relative advantage, compatibility, and complexity vary across product smartness dimensions and across product categories. For example, higher levels of product autonomy are perceived as increasingly advantageous whereas a high level of multifunctionality is perceived disadvantageous. The paper discusses the advantages and pitfalls for each of the five product smartness dimensions and their implications for new product development and concludes with a discussion of the limitations of the study and suggestions for further research.

\section{Introduction}

$\mathrm{T}$ he application of microchips and software is drastically changing the nature of today's consumer products. Modern lawnmowers, for example, operate without manual control. They drive through the garden when cutting the grass, and when the battery runs low the machine autonomously finds its way back to the charging station. In modern houses, light switches have become obsolete because rooms in these houses are equipped with sensors that decide whether the light should be turned on or off.

Address correspondence to: Serge Rijsdijk, RSM Erasmus University, Department Management of Technology and Innovation, P.O. Box 1738, 3000 DR Rotterdam, The Netherlands. E-mail: srijsdijk@rsm.nl.

* The authors acknowledge the Product Development \& Management Association (PDMA) for financing parts of this research project. Also, the authors acknowledge the helpful comments by two anonymous reviewers.
These sensors base their decisions on information about whether there is someone present in the room as well as the amount of available daylight. Numerous other examples of "smart" products containing information technology can be found in the marketplace: autonomous vacuum cleaners, the Sony AIBO robotic dog, personal digital assistants (PDAs), car navigation systems, mobile phones, and digital video cameras. Smart products share the ability to collect, process, and produce information and can be described as "thinking" for themselves. As a result, smart products can, for example, operate autonomously (e.g., the Electrolux autonomous vacuum cleaner), respond to their environment (e.g., the Sony AIBO), or communicate with other products (e.g., PDAs).

Research on smart products can mainly be found within the fields of ergonomics and industrial design. The ergonomics literature addressing product smartness (see, e.g., Feldman, 1995; Freudenthal and 
Mook, 2003; Han et al., 2001) emphasizes the importance of appropriate interface designs. Within the area of industrial design, the focus of the literature is mainly on the new opportunities that product smartness offers to designers and how they should deal with these opportunities (see, e.g., Den Buurman, 1997; Holmquist et al., 2004; Robertson, 1992).

The focus on smart products has so far been limited in the new product development (NPD) literature. Rijsdijk and Hultink (2002) referred to the capabilities of smart products as product smartness and defined this construct as consisting of seven dimensions: autonomy, adaptability, reactivity, multifunctionality, ability to cooperate, humanlike interaction, and personality. In Rijsdijk and Hultink (2003), these authors showed that specific problems are attached to the development of smart products. They conducted a study on consumer perceptions of autonomous products and found that consumers perceive products with higher levels of autonomy as more difficult to understand and use than products with lower levels of autonomy. In addition, consumers perceived products with higher levels of autonomy as more likely to malfunction.

The present paper aims to further investigate product smartness as follows. In addition to the investigation of consumer responses to product autonomy, the paper investigates consumer responses to four additional product smartness dimensions: adaptabil-

\section{BIOGRAPHICAL SKETCHES}

Dr. Serge A. Rijsdijk is assistant professor in the Rotterdam School of Management at Erasmus University in The Netherlands. He received his M.Sc. in industrial and organizational psychology from the Free University of Amsterdam and his Ph.D. from Delft University of Technology. He was awarded with the Best Dissertation Proposal Award 2002 and the Best Paper Award 2002 and 2006 at the Product Development and Management Association (PDMA) International Conference. His Ph.D. research investigated the adoption of new smart products. He currently investigates organizational control in new product development. He has published his work in such journals as the Journal of the Academy of Marketing Science and Journal of Product Innovation Management.

Dr. Erik Jan Hultink is professor of new product marketing in the Faculty of Industrial Design Engineering at Delft University of Technology in The Netherlands. He received his M.Sc. in economics from the University of Amsterdam and his Ph.D. from Delft University of Technology. His research investigates means for measuring and improving the process of new product development and launch. He has published on these topics in such journals as International Journal of Research in Marketing, Journal of the Academy of Marketing Science, Journal of High Technology Management Research, Industrial Marketing Management, $R \& D$ Management, IEEE Transactions on Engineering Management, and Journal of Product Innovation Management. ity, reactivity, multifunctionality, and the ability to cooperate. Numerous smart products that are currently in the marketplace show characteristics corresponding to these smartness dimensions. Insight into how consumers evaluate these dimensions, however, is limited. The second contribution of this paper lies in the investigation of the effects of the product smartness dimensions on consumer perceptions at the product category level. Previous research (Rijsdijk and Hultink, 2003) only studied the effects of product smartness on consumer responses at the aggregate level. The results of the present study show that the effects of product smartness dimensions on consumer responses sometimes differ by product category. These findings deepen the insights into the consequences of product smartness and have significant implications for professionals that develop and market smart products.

The paper continues with a more in-depth discussion of the construct of product smartness. Then it explains the conceptual framework that guided the research and develops the hypotheses for this framework. Next, there is a description of the conjoint study that was conducted and a discussion of the results. Further, implications for NPD are provided, and the limitations of the study addressed. The paper concludes with suggestions for further research.

\section{Product Smartness}

Smart products are products that contain information technology (IT) in the form of, for example, microchips, software, and sensors and that are therefore able to collect, process, and produce information. As a result, smart products show a range of capabilities that can only be found in nonsmart products to a limited extent. Rijsdijk and Hultink (2002) referred to these abilities collectively as product smartness. Product smartness consists of the dimensions of autonomy, adaptability, reactivity, multifunctionality, ability to cooperate, humanlike interaction, and personality. Smart products possess one or more of these dimensions to a lesser or higher degree. Therefore, the overall smartness of a product can be conceptualized as the extent to which it possesses these dimensions. Nonsmart products may show these dimensions to a limited extent (e.g., washing machines can be described as autonomous). However, when such functionality is not based on IT these products are not described as "smart." We thank one of the anonymous reviewers for raising this issue. 
The first dimension of autonomy refers to the extent to which a product is able to operate in an independent and goal-directed way without interference of the user. An example of an autonomous product is the Automower by the Swedish firm Electrolux. This lawn mower is placed in the garden, after which it moves through the garden and cuts the grass all by itself. By setting the limits of the garden with a metal wire the owner ensures that the lawn mower will remain within the limits of the garden. Another example of an autonomous product is the Samsung Robot Vacuum cleaner.

Adaptability is the second dimension of product smartness and refers to a product's ability to improve the match between its functioning and its environment (Nicoll, 1999). This ability has traditionally been considered as an aspect of the intelligence of artifacts (Turing, 1950). For adaptable products, this dimension concerns the ability to respond and adapt to their environment (e.g., the user or the room in which they are placed) over time, which may result in better performance. One example of a product that is adaptable is the Chronotherm IV thermostat developed by Honeywell. From the moment of installation, the Chronotherm IV collects data on the time it takes to raise the temperature in a room. When the user instructs the thermostat to reach a certain room temperature at a certain time, the device will do so on the basis of data it has previously collected.

Reactivity is the third dimension of product smartness and refers to the ability of a product to react to changes in its environment (Bradshaw, 1997). An example of a reactive product is the Philips Hydraprotect hair dryer. This hair dryer lowers the temperature of the air when the humidity of the hair decreases, thereby preventing damage to the hair caused by hot air. Reactive products distinguish themselves from adaptable products in that their reactions to the environment are merely direct responses (reflexes). In contrast to adaptable products, they have no internal models of their environment and are not able to adapt the nature of their reactions over time.

The fourth dimension, multifunctionality, refers to the phenomenon that a single product fulfills multiple functions (Poole and Simon, 1997). The application of information technology in physical products enables a larger set of attributes to be designed into one product (Dhebar, 1996). Modern cell phones, for example, can also be used to play games or send photos and text messages. Similarly, PDAs provide the user with multiple functions such as a calendar, e-mail, games, and a calculator.
The fifth dimension of product smartness is the ability to cooperate with other devices to achieve a common goal. According to Nicoll (1999), the age of discrete products may be ending. Instead, products are becoming more and more like modules with built-in assumptions of their relationships with both users and other products and systems. An increasing number of products are thus able to communicate not only with their users but also among themselves (ibid.). For example, desktop computers cooperate with other products; they can be attached to scanners, printers, musical instruments, video cameras, and so on. Other examples of products that can cooperate are mobile phones and PDAs. The user of these products can write e-mails on the PDA and send these via the mobile phone.

The sixth dimension, humanlike interaction, concerns the degree to which the product communicates and interacts with the user in a natural, human way. Bauer and Mead (1995) suggested that one way of increasing product usability is the application of voice production and recognition. For example, car navigation systems produce speech, and some of them also understand speech. There is no need for users to push any buttons while driving, and the driver is guided to his or her destination through a dialogue with the navigation system.

The final dimension, personality, refers to a smart product's ability to show the properties of a credible character. Bradshaw (1997) discussed the property of a software agent to have a "believable personality and emotional state" (p. 8). Providing an agent with a personality is supposedly beneficial for the user's comprehension of the agent. For example, the paper clip or Einstein assistants in Microsoft Office suggest that "someone" assists the users. For physical products, the property of personality mainly refers to the way users interact with the product. Typical examples of products with a personality are the Furby and Sony's AIBO. These toys express emotions and show certain emotional states.

\section{Conceptual Framework and Hypotheses}

Figure 1 presents the conceptual framework that guided this research. The present study focuses on five product smartness dimensions. An examination of more than 30 smart products currently in the marketplace showed that these smartness dimensions occur most frequently. Autonomy, adaptability, and reactivity can, for example, be found in the Electrolux 


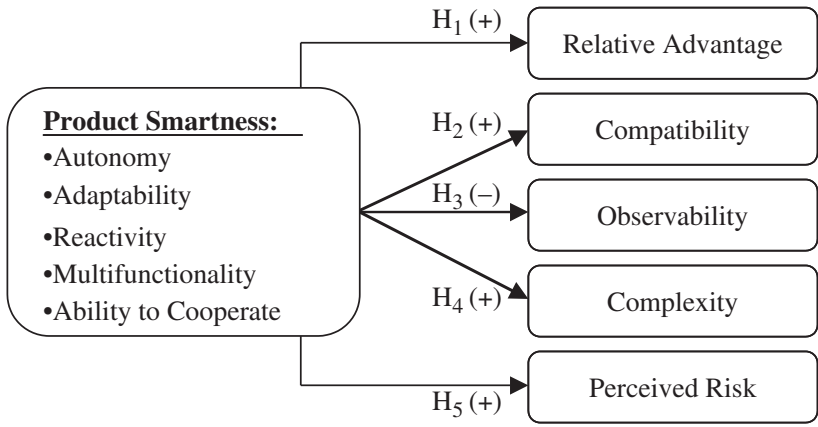

Figure 1. Conceptual Framework

Automower and in the Samsung Robot Vacuum cleaner. Multifunctionality and ability to cooperate can, for example, be found in smart products such as car radios, digital photo and video cameras, Tablet PCs, mobile phones, copiers, and PDAs. Most versions of these products can perform multiple functions and communicate with other products nowadays. The smartness dimensions of humanlike interaction and personality are less common in products that are currently in the marketplace and are therefore not included in the current study.

As it is expected that the five smartness dimensions under investigation influence each of the separate innovation attributes in a similar way, the hypotheses are developed at the overall product smartness level. This is done by innovation attribute.

\section{Relative Advantage}

Relative advantage is defined as the degree to which an innovation is perceived as superior to the idea it supersedes. An innovation can be superior in terms of utility, social prestige (see e.g., Hirschman and Holbrook, 1982), convenience, or other benefits (Rogers, 1995). Several studies (Holak, 1988; Plouffe, Vandenbosch, and Hulland, 2001) showed that relative advantage positively influences the rate of adoption.

It is expected that smarter products will be perceived as offering more relative advantage. With respect to the dimension of autonomy, it is expected that higher levels of autonomy increase the levels of advantage that consumers perceive. This expectation is based on Baber (1996), who described that higher levels of autonomy deliver savings in time and effort. An empirical study by Rijsdijk and Hultink (2003) supported this relationship. It is also expected that products that are able to learn will be perceived as more advantageous. TVs could, for example, gain a higher relative advantage by being able to provide a viewer with personal recommendations that are based on an analysis of previous viewing behavior. The TV may learn which type of shows is frequently watched and provide recommendations on shows that will be on TV at a certain moment. Comparably, products with a higher reactivity are likely to be perceived as offering more advantage. For example, a door that opens when someone approaches it has the advantage over other nonreactive doors in that people do not have to use muscle force to open it.

It is also expected that higher levels of multifunctionality will be perceived as offering more advantage. Each additional function of a product can offer an extra benefit. Also, products that are able to cooperate with a larger number of products are expected to deliver more relative advantage. Previous research (see, e.g., Katz and Shapiro, 1985) showed that for network products, the utility of a network product strongly depends on the number of other users that are in the same network. The utility that a consumer derives from purchasing a telephone, for example, depends on the number of other households or businesses that are in the same telephone network. Analogous to that, it is expected that higher levels of ability to cooperate are associated with a larger utility because they enable the product to cooperate with a larger number of products. For example, a PDA that is able to communicate with both mobile telephones and personal computers has a higher relative advantage than a PDA that can only communicate with a mobile phone. Communications with the mobile phone may, for example, deliver the benefit of exchanging contact information and, as such, have this information available on both devices. In addition to that, communication with a personal computer may enable the exchange of a wider variety of documents and information, such as calendar information, spreadsheets, or text documents. As a result, a PDA that can communicate with both mobile phones and personal computers is likely to offer more advantages than a PDA that only communicates with mobile phones. A positive effect of product smartness on relative advantage is therefore hypothesized:

\section{H1: Product smartness increases perceived relative ad- vantage.}

\section{Compatibility}

The second innovation attribute of compatibility concerns the degree to which an innovation is perceived 
as consistent with existing values, past experiences, and needs of potential adopters (Rogers, 1995). A product that is more compatible is more familiar to the potential adopter and fits more closely with the individual's way of living. Innovations with a higher compatibility have a higher rate of adoption than low compatibility innovations (Holak, 1988; Plouffe et al., 2001).

It is expected that smarter products will be perceived as more compatible. First, products with higher levels of autonomy are likely to be perceived as more compatible. Baber (1996) described how a highly autonomous product may achieve a state of symbiosis with its user in that there is a perfect match between the behavior of the user and the actions of the product. For example, an autonomous vacuum cleaner would start its work when there is nobody in the house and stop its work when someone comes in. Also, products that are able to learn will likely be perceived as more compatible. In fact, it is the basic idea behind the construction of, for example, user profiles to have a product better match the user's needs. A product that is better able to learn will have a more accurate user profile become (Waern, 2004), and, as such, it will be considered as more compatible. More reactive products will also be considered as more compatible in that they respond to their users. For example, the previously described reactive Hydraprotect hair dryer reacts to the humidity of the hair by lowering the temperature of the air. Similarly, properly functioning reactive toilets flush when needed, doors open when someone approaches, and lights switch on when a person enters the room. As such, it is expected that products with higher levels of reactivity will be perceived as more compatible. Finally, it is expected that when a product is able to cooperate with multiple products it can be embedded within a network of other products that a consumer already owns. The PDA that is able to cooperate with, for example, both a mobile telephone and a personal computer is more likely to be perceived as compatible than a PDA that can only communicate with a mobile phone. This leads to the following hypothesis:

H2: Product smartness increases perceived compatibility.

\section{Observability}

Observability refers to the degree to which the consequences of the use of an innovation are visible to others (Rogers, 1995). The results of some innova- tions are easily observed because these products are frequently used in public (e.g., mobile phones). The results of other innovations may be less visible to others because they are mainly used indoors (e.g., vacuum cleaners). Observability positively influences the rate of adoption.

The hypothesis with respect to the impact of product smartness on observability is based on the observation that many smart products contain hidden functionality. Smart products owe a large extent of their functionality to their IT components in the form of, for example, software. Rogers (1995) stated that products with an important software element usually have a slower rate of adoption. In smart products, the relation between the product form and how the product can be used is less obvious than in nonsmart products. In the case of Sony's robotic dog AIBO, for example, some consumers may recognize the little hole in its head as a microphone. However, the presence of this electronic component does not clarify anything about the nature of the words that the AIBO is able to understand. Product form cannot be sufficiently used to clarify which 50 commands and questions the dog understands. Another example is provided by PDAs. A PDA can contain functionality such as a diary, calculator, and address book. However, this functionality is not communicated by the product's form. As a result, consumers may have difficulty in observing a product's functionality (see, e.g., Veryzer, 1995). Accordingly, Roehm and Sternthal (2001) showed that one of the major challenges in marketing PDAs is to help consumers recognize their functionality, particularly functions that are not apparent from the product's surface attributes. Therefore, the following is hypothesized:

H3: Product smartness decreases perceived observability.

\section{Complexity}

Complexity is a fourth innovation characteristic introduced by Rogers (1995). The complexity of an innovation refers to the degree to which an innovation is perceived as relatively difficult to understand and use. Rogers (1995) stated that the complexity of an innovation, as perceived by members of a social system, is negatively related to its rate of adoption.

It is expected that smarter products will be perceived as more complex. This complexity will play a role not only when consumers start using a product but also when they have used the product over a 
longer period of time. Rijsdijk and Hultink (2003) found that consumers perceived higher levels of complexity in product concepts with higher levels of autonomy. With respect to the smartness dimension of adaptability, Alpert et al. (2003) found that users of a user-adaptive interface had difficulty to understand how the interface worked.

Besides complexity that will be perceived at first, it is expected that consumers will also perceive complexity in smart products in later phases of use. Due to the use of IT elements, most functionality of smart products is hidden inside a black box (Bauer and Mead, 1995). Norman (1998, p. 12) stated, "as technology has advanced, we have understood less and less about the inner workings of the systems under our control." A pair of scissors is easy to use because all operating parts are visible and the implications are clear. The holes in the scissors have a size so that only fingers will fit, and the number of possible actions with the scissors is limited (ibid.). For smart products this is not the case. These products can be considered as some of today's most technologically advanced products, and many consumers have difficulties understanding and using these products (Bauer and Mead, 1995). This is also because users do not receive feedback in the form of movements or noise when using these products. Processors and memory chips do their work invisibly and silently (Den Buurman, 1997). For example, only a minority of the owners of DVD recorders can program these devices for delayed recording. Some users do not know that certain functions exist. In other cases, consumers give up on using certain functions because their operation is too difficult to learn and use (Han et al., 2001). Concluding, the following is hypothesized:

H4: Product smartness increases perceived complexity.

\section{Perceived Risk}

Perceived risk as a construct was introduced by Bauer (1960) and later developed by Roselius (1971) and Jacoby and Kaplan (1972) as a multidimensional concept consisting of six components: performance risk, financial risk, social risk, physical risk, psychological risk, and the risk of time loss. The most important dimension of perceived risk is performance risk, and it is associated with inadequate or unsatisfactory performance of the product (Jacoby and Kaplan, 1972). The rate of adoption of an innovation is negatively influenced by the risk that adopters perceive.
It is expected that product smartness increases the performance risk that people perceive. First, technologically sophisticated products generally lead consumers to perceive more risk (Folkes, 1988). In line with that, Rijsdijk and Hultink (2003) showed that perceived risk is positively associated with product autonomy. Smart products frequently perform tasks that were previously performed by their users. It is likely that consumers will not leave these tasks to the products because consumers expect them to fail. The tasks of smart products are also frequently broader and more complex. It is known that a larger chance of failure increases the risks that are perceived (Mitchell and Greatorex, 1993). Also, Morel (2000) found that consumers doubt the quality of multifunctional hybrids (i.e., combinations of two or more separate products), such as $\mathrm{TV}$-video recorder combinations. These findings lead to the following:

\section{H5: Product smartness increases perceived risk.}

\section{Method}

\section{Design}

A conjoint study was conducted with product attributes representing the product smartness dimensions. Two combinations of smartness dimensions were chosen to be investigated on the basis of a study on recent smart product announcements and smart products that are currently in the market. In the remainder of the paper these combinations are described as Combination $A$ and Combination $B$.

The product profiles for Combination A were constructed using attributes representing the product smartness dimensions of autonomy, adaptability, and reactivity, where each attribute had two levels (low/ high). For this combination product profiles were constructed for three different product categories. The full factorial conjoint design with three product attributes of two levels each resulted in eight product profiles for each product category. This design enabled us to investigate both main effects and interaction effects of the product smartness dimensions.

Combination $B$ concerned the dimensions of multifunctionality and ability to cooperate, which were each represented by a product attribute with three different levels (low/medium/high). With a full factorial conjoint design this resulted in nine product descriptions for each of the three product categories. The following section provides further information on the product profiles. 


\section{Stimuli}

Stimuli were verbal product profiles. Previous research showed that, in comparison with pictorial product descriptions, verbal product descriptions facilitate judgment (Vriens et al., 1998). For Combination A, product profiles were constructed for a vacuum cleaner, lawn mower, and washing machine. For Combination B, product profiles were constructed for a refrigerator, digital camera, and washing machine. These product categories were chosen because they are relatively common. As such, it was avoided that respondents' evaluations would be biased because of product unfamiliarity or novelty.

The product profiles were composed of attributes that represented the different levels of the product smartness dimensions. The content of the product attributes was based on smart versions of the specific product categories that can currently be found in the marketplace. However, the nature of the attributes representing the higher levels of the smartness dimensions is sometimes more sophisticated than contemporary functionality, but it may be found in the marketplace in the future. Appendix A provides short descriptions of the product attributes as they were used in the study for each product category. Appendix $\mathrm{B}$ shows the full descriptions of a product profile for the vacuum cleaner representing Combination $\mathrm{A}$ and for the refrigerator representing Combination B.

All product attributes were tested in a series of pretests. The attributes were pretested to ensure that they showed significantly different levels of the corresponding smartness dimensions. In these pretests, all together 164 students in industrial design engineering were presented with the descriptions of the various levels. The students evaluated the descriptions on seven-point multi-item scales that measured the relevant product smartness dimensions. The measurement scales were adopted from Rijsdijk and Hultink (2002). Appendix $\mathrm{C}$ provides an overview of the measurement scales, (Table A1), Cronbach's alphas, and the mean scores for the different levels of the dimensions that resulted from the pretests (Table A2 and Table A3). Post-hoc Scheffé tests indicated that, within each dimension, the ratings for the separate product attributes (as described in Appendix A) differed significantly at the $p<.05$ level.

\section{Sample}

A sample was drawn from a consumer panel containing 1,700 households that participate in consumer research in return for small financial incentives. The sample consisted of 355 respondents who varied in age, educational level, and gender. The questionnaire was sent to the respondents by mail. To ensure that respondents were familiar with the relevant product category, each respondent received a questionnaire on a product from a category that was present in their household (i.e., product ownership for all households is tracked in a database).

\section{Procedure}

Each respondent received eight (for Combination A) or nine (for Combination B) product profiles on cards for one of the six products. After going through a detailed instruction, respondents were provided with descriptions of the innovation attributes and were subsequently asked to rank order the product descriptions on each of the five innovation attributes. They were first asked to rank order the product descriptions from "least complex" to "most complex." Next, the respondents were asked to use the results of the first ranking task to form a new sequence that indicated the degree of complexity of each profile on a sevenpoint scale. Respondents performed the same task for the innovation attributes of relative advantage, compatibility, observability, and perceived risk.

\section{Results and Analysis}

Overall, 184 usable responses were returned implying an effective response rate of $52 \%$. For the products in Combination $\mathrm{A}$, in total 84 responses were received (28 for the washing machine, 24 for the lawn mower, and 32 responses for the vacuum cleaner). For the products in Combination B, 100 responses were received ( 34 for the washing machine, 34 for the refrigerator, and 32 for the digital camera). Next, the results are discussed for each combination.

\section{Combination A: Autonomy, Adaptability, and Reactivity}

For Combination $\mathrm{A}$, the data were analyzed in a $2 \times 2 \times 2 \times 3$ repeated measures analysis of variance (ANOVA) with autonomy (low level vs. high level), adaptability (low level vs. high level), and reactivity (low level vs. high level) as within-subjects factors and product category (washing machine vs. lawn mower vs. vacuum cleaner) as a between-subjects factor. The multivariate tests for all main and interaction effects 
Table 1. Linear Within-Subjects Contrasts for Combination $\mathbf{A}^{\mathrm{a}}$

\begin{tabular}{|c|c|c|c|c|c|c|}
\hline Independent Variables & Dependent Variables & df & $F$ & Sig. & Difference & S.E. \\
\hline \multirow[t]{5}{*}{ Autonomy (AU) } & Relative Advantage & 1 & 39.228 & .000 & 1.40 & .22 \\
\hline & Compatibility & 1 & 1.746 & .190 & 0.37 & .28 \\
\hline & Observability & 1 & 47.550 & .000 & 1.52 & .22 \\
\hline & Complexity & 1 & .035 & .853 & -0.05 & .29 \\
\hline & Perceived Risk & 1 & 115.186 & .000 & 2.05 & .19 \\
\hline \multirow[t]{5}{*}{ AU $\times$ Product Category $(\mathrm{PC})$} & Relative Advantage & 2 & 1.930 & .152 & & \\
\hline & Compatibility & 2 & .537 & .587 & & \\
\hline & Observability & 2 & 2.422 & .095 & & \\
\hline & Complexity & 2 & 2.893 & .061 & & \\
\hline & Perceived Risk & 2 & 5.434 & .006 & & \\
\hline Error (AU) & & 81 & & & & \\
\hline \multirow[t]{5}{*}{ Adaptability (AD) } & Relative Advantage & 1 & 72.348 & .000 & 1.11 & .13 \\
\hline & Compatibility & 1 & 7.565 & .007 & 0.50 & .18 \\
\hline & Observability & 1 & 27.162 & .000 & 0.71 & .14 \\
\hline & Complexity & 1 & 4.880 & .030 & 0.39 & .18 \\
\hline & Perceived Risk & 1 & 51.946 & .000 & 1.21 & .17 \\
\hline \multirow[t]{5}{*}{$\mathrm{AD} \times \mathrm{PC}$} & Relative Advantage & 2 & 20.018 & .000 & & \\
\hline & Compatibility & 2 & 2.857 & .063 & & \\
\hline & Observability & 2 & 3.071 & .052 & & \\
\hline & Complexity & 2 & .240 & .787 & & \\
\hline & Perceived Risk & 2 & 3.470 & .036 & & \\
\hline Error (AD) & & 81 & & & & \\
\hline \multirow[t]{5}{*}{ Reactivity (REAC) } & Relative Advantage & 1 & 40.905 & .000 & 0.84 & .13 \\
\hline & Compatibility & 1 & 15.302 & .000 & 0.59 & .15 \\
\hline & Observability & 1 & 31.911 & .000 & 0.88 & .16 \\
\hline & Complexity & 1 & 6.079 & .016 & 0.38 & .15 \\
\hline & Perceived Risk & 1 & 43.755 & .000 & 0.69 & .10 \\
\hline \multirow[t]{5}{*}{$\mathrm{REAC} \times \mathrm{PC}$} & Relative Advantage & 2 & 8.666 & .000 & & \\
\hline & Compatibility & 2 & 7.941 & .001 & & \\
\hline & Observability & 2 & 2.287 & .108 & & \\
\hline & Complexity & 2 & 3.122 & .049 & & \\
\hline & Perceived Risk & 2 & .050 & .951 & & \\
\hline Error (REAC) & & 81 & & & & \\
\hline
\end{tabular}

${ }^{\text {a }}$ Significant differences at the $p<.05$ level are in bold. df, degrees of freedom. Sig., significance. S.E., standard error.

were significant $(p<.05)$. The current analyses do not include the interactions between the smartness dimensions because preliminary analyses showed that these effects were not significant. Table 1 shows the results for all within-subjects contrasts for Combination A and the estimated mean differences between the low and high levels of autonomy, adaptability, and reactivity on the five innovation attributes (in the "Difference" column) plus the standard errors (in the "S.E." column) of the mean differences. First the main effects that are not associated with any significant interaction effects are discussed. Subsequently, the effects of the smartness dimensions that should be interpreted in the light of their interactions with product category are discussed.

\section{Main Effects: Effects that Hold for All Product Categories for Combination A}

Table 1 shows that, except for the effect of autonomy on the innovation attributes of compatibility and complexity, all main effects of autonomy, adaptability, and reactivity are significant at the $p<.05$ level. A higher level of autonomy is perceived as offering a significantly higher relative advantage $\left(\mathrm{M}_{\text {estimated }}\right.$ difference $=$ $1.40 ; \quad F(1,81)=39.228 ; \quad p<.05)$ and observability $\left(\mathrm{M}_{\text {estimated difference }}=1.52 ; F(1,81)=47.550 ; p<.05\right)$. The effects of autonomy on compatibility $\left(\mathrm{M}_{\text {estimated }}\right.$ difference $=.37 ; F(1,81)=1.746 ; p>.05)$ and complexity $\left(\mathrm{M}_{\text {estimated difference }}=-.05 ; F(1,81)=.035 ; p>.05\right)$ were not significant. The impact of autonomy on perceived risk is addressed in the following section on the interactions between the smartness dimensions and product category.

With respect to the dimension of adaptability, a higher level of this smartness dimension results in an increase in compatibility $\left(\mathrm{M}_{\text {estimated difference }}=.50\right.$; $F(1,81)=7.565 ; p<.05)$ and observability $\left(\mathrm{M}_{\text {estimated }}\right.$ difference $=.71 ; \quad F(1,81)=27.162 ; \quad p<.05)$. Also, a higher level of adaptability is perceived as more complex $\left(\mathrm{M}_{\text {estimated difference }}=.39 ; \quad F(1,81)=4.880\right.$; 
$p<.05)$. The significant effects of adaptability on relative advantage and perceived risk are discussed in the section on the interaction effects.

An increase in the level of reactivity of a product is positively associated with observability $\left(\mathrm{M}_{\text {estimated }}\right.$ difference $=.88 ; F(1,81)=31.911 ; p<.05)$ and perceived risk $\quad\left(\mathrm{M}_{\text {estimated }}\right.$ difference $=.69 ; \quad F(1,81)=43.755$; $p<.05)$. The significant effects of reactivity on relative advantage, compatibility, and complexity are discussed in the following section.

\section{Interaction Effects: Differences across the Product Categories for Combination A}

The interaction between autonomy and product category on perceived risk was significant $(F(2,81)=5.434 ; p<.05)$. Further analysis showed that this main effect was positive for the washing machine $\left(\mathrm{M}_{\text {estimated difference }}=1.19 ;\right.$ S.E. $\left.=.33 ; p<.05\right)$, lawn mower $\left(\mathrm{M}_{\text {estimated difference }}=2.35\right.$; $\mathrm{S} . \mathrm{E} .=.35$; $p<.05)$, and vacuum cleaner $\left(\mathrm{M}_{\text {estimated difference }}\right.$ $=2.60 ;$ S.E. $=.31 ; p<.05)$. The interaction effect, however, indicates that the size of the impact of autonomy on perceived risk varies across product categories.

Adaptability significantly interacted with product category in its impact on relative advantage $(F(2,81)=20.018 ; p<.05)$ and indicated that the impact of adaptability on relative advantage was significant for the washing machine $\left(\mathrm{M}_{\text {estimated }}\right.$ difference $=2.27$; S.E. $=.22 ; p<.05)$ and the vacuum cleaner $\left(\mathrm{M}_{\text {estimated difference }}=.72 ;\right.$ S.E. $\left.=.21 ; p<.05\right)$ but not for the lawn mower $\left(\mathrm{M}_{\text {estimated difference }}=.34\right.$; S.E. $=.24 ; p>.05)$. Possibly, the respondents saw no benefit in a lawn mower that learns to mow the lawn more efficiently over time. In contrast to an autonomous vacuum cleaner, an autonomous lawn mower in operation is less likely to interfere with activities of its owner because it operates outside the house. The significant interaction effect between adaptability and product category on perceived risk $(F(2,81)=3.470$; $p<.05)$ showed that the nature of the effect is positive for the washing machine $\left(\mathrm{M}_{\text {estimated difference }}=1.81\right.$; S.E. $=.29 ; p<.05)$, lawn mower $\left(\mathrm{M}_{\text {estimated difference }}\right.$ $=.73 ;$ S.E. $=.31 ; p<.05)$, and vacuum cleaner $\left(\mathrm{M}_{\text {estimated difference }}=1.09 ;\right.$ S.E. $\left.=.27 ; p<.05\right)$ but that it varies in size across the product categories.

Reactivity interacted significantly with product category in its effect on relative advantage $(F(2,81)=$ $8.666 ; \quad p<.05), \quad$ compatibility $\quad(F(2,81)=7.941$; $p<.05)$, and complexity $(F(2,81)=3.122 ; p<.05)$. The results across product categories showed that for the washing machine $\left(\mathrm{M}_{\text {estimated difference }}=.95\right.$; S.E. $=.23 ; p<.05)$ and vacuum cleaner $\left(\mathrm{M}_{\text {estimated }}\right.$ difference $=1.45$; S.E. $=.21 ; p<.05)$ the effect of reactivity on relative advantage was significant. For the lawn mower it was not significant $\left(\mathrm{M}_{\text {estimated difference }}=\right.$ .11 ; S.E. $=.24 ; p>.05)$. Apparently, the respondents did not find the antitheft alarm beneficial. In line with that, respondents perceived the higher level of reactivity of the washing machine $\left(\mathrm{M}_{\text {estimated }}\right.$ difference $=1.07$; S.E. $=.26 ; p<.05)$ and vacuum cleaner $\left(\mathrm{M}_{\text {estimated difference }}=.99 ;\right.$ S.E. $\left.=.24 ; p<.05\right)$ as more compatible than the low level. This was not the case for the lawn mower $\left(\mathrm{M}_{\text {estimated }}\right.$ difference $=-.29$; S.E. $=.28 ; p>.05)$. The effect of reactivity on complexity was significant for the lawn mower $\left(\mathrm{M}_{\text {estimated difference }}=.91 ;\right.$ S.E. $\left.=.28 ; p<.05\right)$ but not for the washing machine $\left(\mathrm{M}_{\text {estimated difference }}=\right.$ $-.04 ; \quad$ S.E. $=.26 ; \quad p<.05)$ and vacuum cleaner $\left(\mathrm{M}_{\text {estimated difference }}=.27 ;\right.$ S.E. $\left.=.25 ; p>.05\right)$. The differences across the three product categories in terms of their reactivity suggest that consumers prefer a discreet form of reactivity. This form of reactivity does not demand attention from the user and becomes operational only when a certain event occurs. The discussion section elaborates on this finding.

\section{Combination B: Multifunctionality and Ability to cooperate}

For Combination $\mathrm{B}$, the data were analyzed in a $3 \times 3 \times 3$ repeated measures ANOVA with multifunctionality (low level vs. medium level vs. high level) and ability to cooperate (low level vs. medium level vs. high level) as within-subjects factors and product category (washing machine vs. refrigerator vs. digital camera) as a between-subjects factor. All multivariate tests for the main effects and interaction effects were significant at the $p<.05$ level. Also, the Mauchly sphericity tests were significant at this level for both multifunctionality and ability to cooperate for all innovation attributes. It was therefore investigated whether the significance levels that resulted from the Huyn-Feldt correction formula differed from those that assume sphericity (Crowder and Hand, 1990). The differences, however, were negligible, and Table 2 therefore reports the significance levels of all withinsubject contrasts. First, the main effects that do not need to be interpreted in the light of significant interactions with product category are discussed. 
Table 2. Linear Huyhn-Feldt Within-Subject Contrasts for Combination $B^{\text {a }}$

\begin{tabular}{|c|c|c|c|c|c|c|c|c|c|c|}
\hline Independent Variables & Dependent Variables & df & $F$ & Sig. & $\begin{array}{l}\text { Difference } \\
\text { Low vs. } \\
\text { Medium }\end{array}$ & S.E. & $\begin{array}{l}\text { Difference } \\
\text { Low } \\
\text { vs. High }\end{array}$ & S.E. & $\begin{array}{l}\text { Difference } \\
\text { Medium } \\
\text { vs. High }\end{array}$ & S.E. \\
\hline \multirow[t]{5}{*}{ Multifunctionality (MF) } & Relative Advantage & 1 & 4.249 & .042 & 0.78 & .18 & 0.62 & .30 & -.16 & .21 \\
\hline & Compatibility & 1 & 37.199 & .000 & 0.03 & .18 & -1.53 & .25 & -1.56 & .19 \\
\hline & Observability & 1 & 44.699 & .000 & 0.96 & .16 & 1.61 & .24 & 0.65 & .17 \\
\hline & Complexity & 1 & 364.697 & .000 & 1.04 & .10 & 2.72 & .14 & 1.68 & .10 \\
\hline & Perceived Risk & 1 & 325.877 & .000 & 0.92 & .10 & 2.82 & .16 & 1.89 & .12 \\
\hline \multirow[t]{5}{*}{ MF $\times$ Product category $(\mathrm{PC})$} & Relative Advantage & 2 & 2.897 & .060 & & & & & & \\
\hline & Compatibility & 2 & .670 & .514 & & & & & & \\
\hline & Observability & 2 & 1.953 & .147 & & & & & & \\
\hline & Complexity & 2 & .040 & .960 & & & & & & \\
\hline & Perceived Risk & 2 & 3.034 & .053 & & & & & & \\
\hline Error $(\mathrm{MF})$ & & 97 & & & & & & & & \\
\hline \multirow[t]{5}{*}{ Ability to Cooperate (AtC) } & Relative Advantage & 1 & 7.937 & .006 & 0.24 & .16 & 0.68 & .24 & 0.44 & .17 \\
\hline & Compatibility & 1 & 22.895 & .000 & -0.20 & .15 & -.95 & .20 & -0.74 & .17 \\
\hline & Observability & 1 & 25.886 & .000 & 0.49 & .15 & 1.40 & .28 & 0.91 & .17 \\
\hline & Complexity & 1 & 355.390 & .000 & 1.31 & .10 & 2.96 & .16 & 1.64 & .12 \\
\hline & Perceived Risk & 1 & 172.976 & .000 & 1.02 & .11 & 2.35 & .18 & 1.32 & .12 \\
\hline \multirow[t]{5}{*}{$\mathrm{AtC} \times \mathrm{PC}$} & Relative Advantage & 2 & 8.154 & .001 & & & & & & \\
\hline & Compatibility & 2 & 51.280 & .000 & & & & & & \\
\hline & Observability & 2 & 1.033 & .360 & & & & & & \\
\hline & Complexity & 2 & .542 & .584 & & & & & & \\
\hline & Perceived Risk & 2 & 8.311 & .000 & & & & & & \\
\hline Error (AtC) & & 97 & & & & & & & & \\
\hline
\end{tabular}

${ }^{a}$ Significant differences at the $p<.05$ level are in bold. df, degrees of freedom. Sig., significance. S.E., standard error.

Subsequently, the paper discusses the effects that differed by product category.

\section{Main Effects: Effects that Hold for All Product Categories for Combination B}

Multifunctionality significantly influences relative advantage $(F(1,97)=4.249 ; p<.05)$. More specifically, the medium level is perceived as providing a significantly higher relative advantage than the low level $\left(\mathrm{M}_{\text {estimated difference }}=.78 ; p<.05\right)$. The differences across the high versus low and medium levels were not significant. As such, the relationship between multifunctionality and relative advantage approaches that of an inverted U-shape. Additional analyses showed that, in line with this, the quadratic within-subject contrast was also significant $(F(1,97)=13.164$; $p<.05)$. Also, for the effect of multifunctionality on compatibility both the linear contrast $(F(1,97)=$ $37.199 ; p<.05)$ and quadratic contrast $(F(1,97)=$ 32.558; $p<.05)$ were significant. Further analysis showed that the high level of multifunctionality was perceived as significantly less compatible than the low $\left(\mathrm{M}_{\text {estimated difference }}=-1.53 ; p<.05\right)$ and medium level of multifunctionality $\left(\mathrm{M}_{\text {estimated difference }}=\right.$ $-1.56 ; p<.05)$. As such, the relationship between multifunctionality and compatibility can be described as quadratic. Higher levels of multifunctionality were also perceived as having increasingly higher levels of observability $(F(1,97)=44.699 ; p<.05)$. Table 2 also shows that all three levels of multifunctionality were perceived as significantly different in terms of complexity $(F(1,97)=364.697 ; p<.05)$ and perceived risk $(F(1,97)=325.877 ; p<.05)$. Higher levels of multifunctionality were perceived as increasingly more complex and risky.

All three levels of ability to cooperate were perceived as significantly different from each other in terms of observability $(F(1,97)=25.886 ; p<.05)$ and complexity $(F(1,97)=355.390 ; p<.05)$. Higher levels of ability to cooperate were perceived as offering increasingly more observable advantages but also as increasingly complex. As such, the effects of ability to cooperate have two sides. The effects of ability to cooperate on relative advantage, compatibility, and perceived risk are explained in terms of their interactions with product category in the following section.

\section{Interaction Effects: Differences across the Product Categories for Combination B}

There were no significant interaction effects between multifunctionality and product category on any of the innovation attributes. Ability to cooperate was found 
to interact with product category in its effect on relative advantage $(F(2,97)=8.154 ; p<.05)$. The results showed that this effect was not significant for the washing machine and refrigerator. However, for the digital camera, increases in ability to cooperate were perceived as delivering significantly higher levels of relative advantage $\left(\mathrm{M}_{\text {low level }}=2.86 ; \mathrm{M}_{\text {medium level }}=\right.$ 4.27; $\mathrm{M}_{\text {high level }}=4.48$ ).

Ability to cooperate was also found to interact with product category in its effect on compatibility $(F(2,97)=51.280 ; p<.05)$. The three levels of ability to cooperate were perceived as significantly different from each other for the washing machine $\left(\mathrm{M}_{\text {low level }}=4.55 ; \mathrm{M}_{\text {medium level }}=3.46 ; \mathrm{M}_{\text {high level }}=\right.$ 2.66) and the refrigerator $\left(\mathrm{M}_{\text {low }}\right.$ level $=4.87$; $\mathrm{M}_{\text {medium level }}=3.94 ; \mathrm{M}_{\text {high level }}=2.06$ ). As such, the effect of ability to cooperate on compatibility was negative for these product categories. For the digital camera, however, the effect was opposite as the low level of ability to cooperate was perceived as significantly less compatible than the medium $\left(\mathrm{M}_{\text {estimated }}\right.$ difference $\left.=1.41 ; p<.05\right)$ and high $\left(\mathrm{M}_{\text {estimated difference }}=1.84, p<.05\right)$ levels. The difference between the medium level and high level in terms of compatibility was not significant. For the washing machine and refrigerator, higher levels of ability to cooperate are perceived as less compatible. However, consumers perceived the medium and high level of ability to cooperate in the digital camera as significantly more compatible than the low level.

Finally, the results showed that ability to cooperate significantly interacts with product category in its effect on perceived risk $(F(2,97)=8.311 ; p<.05)$. At the product category level, this effect is significant and positive for the washing machine $\left(\mathrm{M}_{\text {low level }}=3.10\right.$; $\mathrm{M}_{\text {medium level }}=4.37 ; \mathrm{M}_{\text {high level }}=5.73$ ), refrigerator $\left(\mathrm{M}_{\text {low level }}=2.71 ; \mathrm{M}_{\text {medium level }}=4.07 ; \mathrm{M}_{\text {high level }}=\right.$
5.78), and digital camera $\left(\mathrm{M}_{\text {low level }}=3.25 ; \mathrm{M}_{\text {medium }}\right.$ level $\left.=3.69 ; \mathrm{M}_{\text {high level }}=4.59\right)$. Apart from the low and medium level of the digital camera $\left(\mathrm{M}_{\text {estimated }}\right.$ difference $=.44 ; p>.05$ ), all levels of ability to cooperate are perceived as significantly different from each other in terms of perceived risk. Thus, higher levels of ability to cooperate are generally associated with higher levels of perceived risk. The results of the study are discussed further in the following section.

\section{Discussion and Managerial Implications}

This paper extends the product smartness literature by investigating consumer responses to product profiles that combine multiple product smartness dimensions. Two combinations of smartness dimensions are investigated. The first combination includes the dimensions of autonomy, adaptability, and reactivity. This combination is applied to three product categories: vacuum cleaners, lawn mowers, and washing machines. The second combination concerns the dimensions of multifunctionality and ability to cooperate and is applied to the categories of digital cameras, refrigerators, and washing machines. The consumer responses are measured in terms of the innovation attributes of relative advantage, compatibility, observability, complexity, and perceived risk. It is hypothesized that all product smartness dimensions positively influence relative advantage, compatibility, complexity, and perceived risk. A negative impact of the smartness dimensions on observability is hypothesized.

The results of a conjoint study performed among 184 consumers partly confirm the hypotheses. Table 3 provides an overview of the results. Higher levels of the product smartness dimensions always result in higher levels of perceived risk. Also, higher levels of product smartness generally increase perceived rela-

Table 3. Overview of the Results

\begin{tabular}{|c|c|c|c|c|c|}
\hline & Relative Advantage (H1) & Compatibility (H2) & Observability (H3) & Complexity (H4) & Perceived Risk (H5) \\
\hline Autonomy & $+^{\mathrm{a}}$ & n.s. ${ }^{b}$ & + & n.s. & + \\
\hline Adaptability & Product dependent ${ }^{\mathrm{c}}$ & + & + & + & + \\
\hline Reactivity & Product dependent & Product dependent & + & Product dependent & + \\
\hline Multifunctionality & & & + & + & + \\
\hline Ability to cooperate & Product dependent & Product dependent & + & + & + \\
\hline Hypothesis & Partly confirmed & Partly confirmed & Not confirmed & Partly confirmed & Fully confirmed \\
\hline
\end{tabular}


tive advantage, compatibility, and complexity. However, these results often vary by smartness dimension and by product category. Also, it is found that, opposite to expectations, higher levels of product smartness result in higher levels of observability.

Overall, the study deepens the insight into how consumers perceive contemporary and future smart products. A number of managerial implications that follow from the present research are provided next. These implications are ordered by product smartness dimension because each dimension has its own unique pitfalls and advantages. The paper concludes with a discussion of the limitations of the study and suggestions for further research.

\section{Product Autonomy: A Potential Complexity Reducer}

As expected, product autonomy increases the advantages that consumers perceive in a smart product. Also, consumers consider these advantages as more observable. As such, creating products with higher levels of autonomy is likely to result in products that deliver benefits that cannot be found in competing products. No significant main effect of autonomy on complexity is found. Because this finding is different from previous research, this effect was studied for the washing machine $\left(\mathrm{M}_{\text {estimated difference }}=-1.03\right.$; S.E. $=$ $.50 ; p<.05)$, lawnmower $\left(\mathrm{M}_{\text {estimated difference }}=.36\right.$; S.E. $=.54 ; p>.05)$, and vacuum cleaner $\left(\mathrm{M}_{\mathrm{estimated}}\right.$ difference $=.50 ;$ S.E. $=.47 ; p>.05)$ separately. For the lawn mower and vacuum cleaner, the effect of autonomy on complexity is not significant. However, for the washing machine this effect is significant and negative. This finding is opposite to the results of Rijsdijk and Hultink (2003), where autonomy was found to positively influence complexity.

Possibly, the nonsignificant effect of autonomy on complexity at the aggregate level can be explained by the fact that for the lawn mower and vacuum cleaner the lowest level of autonomy already shows some autonomy. In the study by Rijsdijk and Hultink (2003), the levels of autonomy varied from zero (no autonomy) to high autonomy. The complexity that consumers perceive may substantially increase when the autonomy of a product is raised from the zero level up to a medium level. Consumers may not perceive a significant difference in terms of complexity between products with medium levels and high levels of autonomy.

For the washing machine, the negative impact of autonomy on complexity may be explained by the fact that the high autonomy machine takes over a complex decision-making task from the user. The high autonomy washing machine selects the appropriate washing program and starts this program. Consumers appear to appreciate this sort of autonomy. In contrast, the low autonomy machine only gives an advice on the appropriate washing program and the user still has to decide which program to use. As such, the results suggest that autonomous products that take over a complex cognitive task from the user will be perceived as less complex. The study by Rijsdijk and Hultink (2003) showed a significant positive impact of autonomy on complexity. However, that study investigated autonomy that takes over physical tasks from the user. As such, the results suggest that autonomy that takes over cognitive tasks is perceived as decreasing complexity and, through that, increases the probability of product adoption. For autonomous products that take over physical tasks this is not the case.

As with all product smartness dimensions, product autonomy increases the risk that consumers perceive. This finding is in line with the results from previous research (Rijsdijk and Hultink, 2003) and indicates that new product developers should aim to reduce this negative effect. This can, for example, be done by an adaptation of the design of the new product. Providing an autonomous product with indicators that inform the user about what the product is doing may reduce risk perceptions.

\section{Product Adaptability: Extensive Idea Testing}

The findings indicate that adaptability has its advantages in that it increases the perceived levels of compatibility and observability. A product that is adaptable is likely to better fit with consumers' needs. On the other hand, adaptability increases complexity and perceived risk and thus asks for a proficient design and marketing of the product. The most conspicuous result concerning this dimension, however, is that its impact on relative advantage varies by product category. Adaptability has a significantly positive impact on relative advantage for the washing machine. This effect was also significant for the vacuum cleaner but not for the lawn mower, although the operationalization of adaptability was similar for both products. This operationalization implies that the products learn the shortest route through the garden or through the house. Apparently, consumers perceive it useful when a vacuum cleaner moves through the house as quickly as possible and disturbs 
the household members as little as possible. For the lawn mower, this ability is not perceived as beneficial because the mower operates in the garden and is less likely to disturb anyone.

This finding suggests that extensive idea testing for adaptable functionality is important. Although many ideas for adaptable products may seem appealing, their advantages are not directly obvious to all consumers. New product developers may, for example, use information acceleration (IA) techniques for the testing of new smart product ideas (Urban, Weinberg, and Hauser, 1996). The idea behind IA is to place consumers in a multimedia virtual environment and provide them with information on a new product. Multiple virtual prototypes of a product can be developed with different levels of adaptability. Consumers can evaluate these different levels and thereby provide companies with information on the appropriateness of adaptable functionality.

\section{Reactivity: Preferably Dormant}

The findings with respect to reactivity largely differ by product category. Reactivity positively influences relative advantage, compatibility, observability, and perceived risk for the washing machine and vacuum cleaner. There is no significant impact of reactivity on complexity for these products. For the lawn mower, the reactive functionality also positively influences observability and perceived risk. However, reactivity does not affect relative advantage and compatibility for this product, but it does have a significant positive impact on complexity. As such, new product developers need to carefully design and market reactive products because they may be perceived as likely to malfunction.

In addition, the nature of the reactivity appears to affect consumer perceptions. The washing machine and vacuum cleaner in this study are both equipped with a relatively discreet form of reactivity. The washing machine signals if it is overloaded with laundry, and the vacuum cleaner selects extraordinary large objects into a separate compartment. The lawn mower, however, reacts with an antitheft alarm if someone removes it from the area where it is normally located. Switching off the alarm would require the use of a special code and demands user involvement. This form of reactivity is not perceived as advantageous and compatible, but it does increase the complexity that consumers perceive. The art of creating reactive products therefore appears to be to develop dormant functionality that remains unnoticed as long as needed. Once it becomes necessary, reactive functionality should require little user involvement. As a result, this functionality will be perceived as advantageous and compatible and not complex.

\section{Multifunctionality: Step by Step}

Multifunctionality increases the complexity and risk that consumers perceive. Multifunctionality has a positive impact on observability but only a limited positive impact on relative advantage. The highest level of multifunctionality is not perceived as delivering a higher relative advantage than the two lower levels. In contrast to expectations, the highest level of multifunctionality is perceived as significantly less compatible than the low and medium levels. These results suggest that the benefits of adding functions to a product are limited. There appears to be a maximum level of multifunctionality that consumers appreciate, and this finding supports the idea to introduce products into the marketplace only with a moderate increase in multifunctionality. This suggestion is in line with developments that one sees in practice. Philips Electronics, for example, recognized that many consumers have trouble dealing with products that fulfill many functions. Therefore, in 2004, Philips Electronics launched its new marketing campaign that proclaims "Sense and simplicity" (http://www. philips.com). Consumer research may provide insight into what level of multifunctionality is still acceptable for consumers and what level demands too much adaptation. In line with findings of such research, developers may want to implement their ideas for multifunctional products in a stepwise manner and to provide consumers with the opportunity to get used to certain levels of product smartness. Once the market is ready for higher levels, new generations with such levels can be introduced into the marketplace. As with the stepwise introduction of new product features (Thoelke, Hultink, and Robben, 2001), a stepwise introduction of extra functions may also be interesting from a strategic perspective because it may provide competitive advantages over a longer period of time.

\section{Ability to Cooperate: Take into Account Consumers' Product Conceptions}

As with all other smartness dimensions, ability to cooperate positively influences observability, complexity, and perceived risk. Furthermore, the ability to 
cooperate generally has a negative impact on compatibility and only affects relative advantage in a limited way. More specifically, the results show that the ability to cooperate is more problematic for the washing machine and refrigerator than for the digital camera. This result may be explained by the fact that the core function of a digital camera demands this product to be multifunctional and able to cooperate with other products. This is not the case for the washing machine and refrigerator. In addition, consumers have certain ideas of what a product category should and should not do. For some product categories, these ideas may be more versatile than for other product categories. In the present research, ideas about what a washing machine and refrigerator should do may be less versatile than for a digital camera. As such, new product developers need to take this into account and investigate the extent to which consumers are susceptible for modifications of specific product categories. For some product categories, it may be difficult for consumers to accept that their functionality is extended with the ability to cooperate with other products. When consumers have relatively negative attitudes toward products that cooperate with other products, new product developers may want to emphasize the benefits that this cooperation delivers. Preferably, consumers need to be convinced of these benefits through product tryouts and demonstrations.

\section{Conclusions}

Overall, it can be concluded that product smartness has its advantages in that it may result in new and fruitful product benefits. Important disadvantages that are attached to product smartness are increased levels of complexity and perceived risk. The extent to which advantages and disadvantages play a role varies by product smartness dimension and sometimes by product. Whereas the smartness dimension of autonomy has relatively few disadvantages, the dimensions of multifunctionality and ability to cooperate are more problematic. All dimensions, however, deliver certain benefits and for most of their disadvantages solutions exist. The current article provided several suggestions on how to deal with these disadvantages and, as such, it delivers useful input for the developers of new smart products. As with all research, however, the study suffers from several limitations. Also, it has raised new questions. The limitations and suggestions for further research are discussed next.

\section{Limitations}

A limitation of the present study is that it only investigates consumer perceptions of smart products in an experimental setting using verbal product descriptions. Although this setting enables a controlled investigation of the effects of product smartness and although previous research showed that consumers are better able to judge product concepts when they are only described verbally (Vriens et al., 1998), generalization of the results to actual consumer behavior remains uninvestigated. Also, the study did not include factors such as brand, price, and product form, which may well have a dominant impact on actual smart product adoption behavior.

\section{Suggestions for Further Research}

The current paper has further expanded the knowledge on how consumers respond to product smartness. Some of the results, however, were not in accordance with previous research. Rijsdijk and Hultink (2003) found that an increase in product autonomy causes an increase in perceived complexity. The current study shows that product autonomy can also decrease the complexity that consumers perceive. This difference is explained by hypothesizing that autonomy reduces complexity when the smart product takes over a complex cognitive task. Further research should investigate whether this explanation holds.

Also, future research into smart products should investigate how other product characteristics such as product form, brand, or price influence the perception of smart products. The form of a product may, for example, help in reducing consumers' perceptions of complexity by maintaining a more conventional design compared with a more innovative design. Also, strong brands or higher prices may reduce the risk that consumers perceive in smart products.

Finally, future research could also explore whether adopters of smart products have special characteristics. The analyses did not take respondents' characteristics such as social class, lifestyle, or values into account. However, the adoption literature (see, e.g., Andrews and Currim, 2003) suggests that the nature of the adopter of an innovation is partially a function of the characteristics of the innovation itself. It could very well be the case that consumers with certain specific characteristics are more likely to adopt smart products than other consumers. Further research into this issue is important for segmentation and targeting 
purposes. As a result of such research, new smart products may become more successful.

\section{References}

Alpert, S.R., Karat, J., Karat, C.M., Brodie, C., and Vergo, J.G. (2003). User Attitudes Regarding a User-Adaptive Ecommerce Web Site. User Modeling and User-Adapted Interaction 13(4):373396 (November).

Andrews, R.L. and Currim, I.S. (2003). Recovering and Profiling the True Segmentation Structure in Markets: An Empirical Investigation. International Journal of Research in Marketing 20(2):177-192 (June).

Baber, C. (1996). Humans, Servants and Agents: Human Factors of Intelligent Products. Paper presented at the Conference on Artificial intelligence in Consumer and Domestic Products, London.

Bauer, R.A. (1960). Consumer Behavior as Risk Taking. In: Dynamic Marketing for a Changing World, ed. R. Hancock. Chicago: American Marketing Association, 389-398.

Bauer, S. and Mead, P. (1995). After You Open the Box: Making Smart Products More Usable, Useful, and Desirable through Interactive Technology. Design Management Journal 6(4):21-27 (Fall).

Bradshaw, J.M. (1997). Software Agents. Menlo Park, CA: American Association for Artificial Intelligence.

Crowder, M.J. and Hand, D.J. (1990). Analysis of Repeated Measures. London: Chapman and Hall.

Den Buurman, R. (1997). User-Centered Design of Smart Products. Ergonomics 40(10):1159-1169 (October).

Dhebar, A. (1996). Information Technology and Product Policy: "Smart" Products. European Management Journal 14(5):477-485 (October).

Feldman, L.P. (1995). Increasing the Usability of High-Tech Products through Design Research. Design Management Journal 5:27-33 (Fall).

Folkes, V.S. (1988). The Availability Heuristic and Perceived Risk. Journal of Consumer Research 15(1):13-23 (June).

Freudenthal, A. and Mook, R. (2003). The Evaluation of an Innovative Intelligent Thermostat Interface: Universal Usability and Age Differences. Cognition, Technology \& Work 5(1):55-66 (April).

Han, S.H., Yun, M.H., Kwahk, J., and Hong, S.W. (2001). Usability of Consumer Electronic Products. International Journal of Industrial Ergonomics 28(3-4):143-151 (September-October).

Hirschman, E.C. and Holbrook, M.B. (1982). Hedonic Consumption: Emerging Concepts, Methods and Propositions. Journal of Marketing 46(3):92-101 (Summer).

Holak, S.L. (1988). Determinants of Innovative Durables Adoption: An Empirical Study with Implications for Early Product Screening. Journal of Product Innovation Management 5(1):50-69 (March).

Holmquist, L.E., Gellersen, H.-W., Kortuem, G., Schmidt, A., Strohbach, M., and Antifakos, S., et al (2004). Building Intelligent Environments with Smart-Its. IEEE Computer Graphics and Applications 24(1):56-64 (January-February).

Jacoby, J. and Kaplan, L.B. (1972). The Components of Perceived Risk. In: Third Annual Conference of the Association for Consumer
Research, ed. M. Venkatesan. College Park, MD: Association for Consumer Research, 382-393.

Katz, M.L. and Shapiro, C. (1985). Network Externalities, Competition, and Compatibility. American Economic Review 75(3):424-440 (June).

Mitchell, V.W. and Greatorex, M. (1993). Risk Perception and Reduction in the Purchase of Consumer Services. Service Industries Journal 13(4):179-200 (October).

Morel, K.P.N. (2000). Consumers' Reactions to Ambiguous Product Information, Ph.D. diss., Delft University of Technology, The Netherlands.

Nicoll, D. (1999). Taxonomy of Information Intensive Products, Working Paper, University of Edinburgh Management School.

Norman, D.A. (1998). The Design of Everyday Things. London: MIT Press.

Plouffe, C.R., Vandenbosch, M., and Hulland, J. (2001). Intermediating Technologies and Multi-Group Adoption: A Comparison of Consumer and Merchant Adoption Intentions toward a New Electronic Payment System. Journal of Product Innovation Management 18(2):65-81 (March).

Poole, S. and Simon, M. (1997). Technological Trends, Product Design and the Environment. Design Studies 18(3):237-248 (July).

Rijsdijk, S.A. and Hultink, E.J. (2002). The Impact of Product Smartness on Consumer Satisfaction through Product Advantage, Compatibility, and Complexity. Paper presented at the Proceedings of the 13th PDMA Research Conference, Orlando.

Rijsdijk, S.A. and Hultink, E.J. (2003). "Honey, Have You Seen Our Hamster?" Consumer Evaluations of Autonomous Domestic Products. Journal of Product Innovation Management 20(3):204-216 (May).

Robertson, A. (1992). Technolust versus Creative Design: Some Implications of "Intelligent" Products for Design. Paper presented at the IEE Colloquium on Intelligent Consumer Products, London.

Roehm, M.L. and Sternthal, B. (2001). The Moderating Effect of Knowledge and Resources on the Persuasive Impact of Analogies. Journal of Consumer Research 28(2):257-272 (September).

Rogers, E.M. (1995). Diffusion of Innovations, (4th ed.). New York: Free Press.

Roselius, T. (1971). Consumer Ranking of Risk Reduction Methods. Journal of Marketing 35(1):56-61 (January).

Thoelke, J.M., Hultink, E.J., and Robben, H.S. (2001). Launching New Product Features: A Multiple Case Examination. Journal of Product Innovation Management 18(1):3-14 (January).

Turing, A.M. (1950). Computing Machinery and Intelligence. Mind 59:433-460.

Urban, G.L., Weinberg, B.D., and Hauser, J.R. (1996). Premarket Forecasting of Really-New Products. Journal of Marketing 60(1):47-60 (January).

Veryzer, R.W. (1995). The Place of Product Design and Aesthetics in Consumer Research. Advances in Consumer Research 22:641-645.

Vriens, M., Loosschilder, G.H., Rosbergen, E., and Wittink, D.R. (1998). Verbal Versus Realistic Pictorial Representations in Conjoint Analysis with Design Attributes. Journal of Product Innovation Management 15(5):455-467 (September).

Waern, A. (2004). User Involvement in Automatic Filtering: An Experimental Study. User Modeling and User-Adapted Interaction 14(2-3):201-237 (June). 


\section{Appendix A. Short Descriptions of the Product Attributes}

\section{Combination A}

\begin{tabular}{|c|c|c|c|}
\hline $\begin{array}{l}\text { Product } \\
\text { Category }\end{array}$ & Dimension & Level & Attributes \\
\hline \multirow[t]{6}{*}{$\begin{array}{l}\text { Vacuum } \\
\text { Cleaner }\end{array}$} & \multirow[t]{2}{*}{ Autonomy } & Low & $\begin{array}{l}\text { Autonomous vacuum cleaner that has to be started and recharged by } \\
\text { its owner. }\end{array}$ \\
\hline & & High & Autonomous vacuum cleaner that starts itself and also recharges itself. \\
\hline & \multirow[t]{2}{*}{ Adaptability } & Low & This vacuum cleaner chooses a random route. \\
\hline & & High & $\begin{array}{l}\text { This vacuum cleaner learns the optimal route through the house over } \\
\text { time. }\end{array}$ \\
\hline & \multirow[t]{2}{*}{ Reactivity } & Low & Vacuums normally. \\
\hline & & High & $\begin{array}{l}\text { Vacuums normally and sorts out relatively big or heavy objects such } \\
\text { as earrings or coins. }\end{array}$ \\
\hline \multirow[t]{6}{*}{$\begin{array}{l}\text { Lawn } \\
\text { Mower }\end{array}$} & \multirow[t]{2}{*}{ Autonomy } & Low & $\begin{array}{l}\text { Autonomous lawn mower that has to be started and recharged by its } \\
\text { owner. }\end{array}$ \\
\hline & & High & Autonomous lawn mower that starts itself and also recharges itself. \\
\hline & \multirow[t]{2}{*}{ Adaptability } & Low & This lawn mower chooses a random route \\
\hline & & High & $\begin{array}{l}\text { This lawn mower learns the optimal route through the garden over } \\
\text { time. }\end{array}$ \\
\hline & \multirow[t]{2}{*}{ Reactivity } & Low & No antitheft alarm. \\
\hline & & High & $\begin{array}{l}\text { Equipped with antitheft alarm that needs to be switched off with a } \\
\text { secret code when using the lawn mower outside the area where it nor- } \\
\text { mally operates. }\end{array}$ \\
\hline \multirow[t]{6}{*}{$\begin{array}{l}\text { Washing } \\
\text { Machine }\end{array}$} & \multirow[t]{2}{*}{ Autonomy } & Low & $\begin{array}{l}\text { Washing machine itself chooses what kind of detergent to use (for } \\
\text { colored or white laundry). User chooses washing program. }\end{array}$ \\
\hline & & High & $\begin{array}{l}\text { Washing machine itself chooses what kind of detergent to use (for } \\
\text { colored or white laundry) and washing program. }\end{array}$ \\
\hline & \multirow[t]{2}{*}{ Adaptability } & Low & Always uses same amount of detergent. \\
\hline & & High & $\begin{array}{l}\text { Learns over time how much detergent is needed for certain amounts of } \\
\text { laundry. }\end{array}$ \\
\hline & \multirow[t]{2}{*}{ Reactivity } & Low & No alarm in case of too much laundry in machine. \\
\hline & & High & Alarm in case of too much laundry in machine. \\
\hline
\end{tabular}

\section{Combination B}

Product

Category Dimension Level Description

Refrigerator Multifunc- Low Cools.

tionality

Medium Cools and has a display that provides access to a digital cookbook.

High Cools and has a display that provides access to a digital cookbook, health tips concerning food, TV, radio stations, and the Internet. 


\section{Appendix A. (Contd.)}

\begin{tabular}{|c|c|c|c|}
\hline $\begin{array}{l}\text { Product } \\
\text { Category }\end{array}$ & Dimension & Level & Description \\
\hline & $\begin{array}{l}\text { Ability to } \\
\text { cooperate }\end{array}$ & Low & $\begin{array}{l}\text { Contains a scanner and shows all products in the refrigerator on a } \\
\text { display on the outside of the refrigerator. }\end{array}$ \\
\hline & & Medium & $\begin{array}{l}\text { Has a display that shows all products in the refrigerator. The in- } \\
\text { formation on the content of the refrigerator can also be retrieved by } \\
\text { cell phone. }\end{array}$ \\
\hline & & High & $\begin{array}{l}\text { Has a display that shows all products in the refrigerator. The in- } \\
\text { formation on the content of the refrigerator can also be retrieved by } \\
\text { cell phone, personal computer, or TV. The device is also connected } \\
\text { to security cameras around the house and can show their images. }\end{array}$ \\
\hline \multirow[t]{6}{*}{$\begin{array}{l}\text { Digital } \\
\text { Camera }\end{array}$} & $\begin{array}{l}\text { Multifunc- } \\
\text { tionality }\end{array}$ & Low & Photo camera. \\
\hline & & Medium & Photo and video camera in one. \\
\hline & & High & $\begin{array}{l}\text { Photo and video camera in one and can also be used to edit the } \\
\text { pictures and films, make sound recordings, and play mini CDs. }\end{array}$ \\
\hline & $\begin{array}{l}\text { Ability to } \\
\text { cooperate }\end{array}$ & Low & Has floppy disk with large capacity. \\
\hline & & Medium & $\begin{array}{l}\text { Has floppy disk with large capacity and can be connected to per- } \\
\text { sonal computer. }\end{array}$ \\
\hline & & High & $\begin{array}{l}\text { Has floppy disk with large capacity and can be connected to per- } \\
\text { sonal computer, TV, video recorder, and printer. }\end{array}$ \\
\hline \multirow[t]{6}{*}{$\begin{array}{l}\text { Washing } \\
\text { Machine }\end{array}$} & $\begin{array}{l}\text { Multifunc- } \\
\text { tionality }\end{array}$ & Low & Washes. \\
\hline & & Medium & $\begin{array}{l}\text { Washes, can give advice on washing based on the color, type of } \\
\text { fabric, and dirtiness of the laundry. }\end{array}$ \\
\hline & & High & $\begin{array}{l}\text { Washes, can give advice on washing based on the color, type of } \\
\text { fabric, and dirtiness of the laundry, and has Internet functionality } \\
\text { that, for example, enables additional advice concerning washing. }\end{array}$ \\
\hline & $\begin{array}{l}\text { Ability to } \\
\text { cooperate }\end{array}$ & Low & Has a digital display. \\
\hline & & Medium & Has a digital display and can be started using a cell phone. \\
\hline & & High & $\begin{array}{l}\text { Has a digital display and can be started using a cell phone, personal } \\
\text { computer, or Internet. When finished, the machine can send a signal } \\
\text { to a cell phone or TV. }\end{array}$ \\
\hline
\end{tabular}




\section{Appendix B. Examples of Two Full Product Profiles}

\section{Combination A: Example of a Card with a Vacuum Cleaner Description}

\section{Vacuum Cleaner $\mathbf{X}$}

\section{Semiautonomous}

This vacuum cleaner is a wireless vacuum cleaner that automatically drives through the house after the user has started it. Due to the use of sensors the vacuum cleaner never collides into other objects. The vacuum cleaner stops when the battery is empty. The user then has to reload the vacuum cleaner by placing it in the charging station and restarting it when the battery is recharged.

\section{Random route}

This vacuum cleaner lets its route through the house depend on the objects it runs into. Therefore, the route of the vacuum cleaner can be different for every time it vacuums.

\section{Filter system}

This vacuum cleaner vacuums everything a normal vacuum cleaner vacuums but reacts to relatively big or heavy objects, such as an earring, by separating them from the dust. These objects end up in a separate compartment.

\section{Combination B: Example of a Card with a Refrigerator Description}

\section{Refrigerator $\mathrm{X}$}

\section{Cooling function + cookbook}

This refrigerator cools your products just like any other refrigerator. By means of a build-in display you also have access to a digital cookbook.

\section{Display}

This refrigerator is equipped with a scanner that is able to recognize every product on the basis of their form, color, or barcode. On a display on the outside of the refrigerator one can read which products the refrigerator contains. 


\section{Appendix C. Pilot Measures and Results}

\section{Table A1. Measurement Scales ${ }^{\mathrm{a}}$ and Cronbach's Alphas}

Autonomy $(\alpha=0.81)$

1. This product goes its own way.

2. This product takes the initiative.

3. This product works independently.

4. This product does things by itself.

Adaptability $(\alpha=0.95)$

1. This product can learn.

2. This product improves itself.

3. This product acts on the basis of previously collected information.

4. This product delivers a better performance over time.

Reactivity $(\alpha=0.89)$

1. This product keeps an eye on its environment.

2. This product directly adapts its behavior to the environment.

3. This product observes its environment.

Multifunctionality $(\alpha=0.82)$

1. This product has multiple functions.

2. This product can do a lot.

3. This product performs multiple tasks.

4. This product fulfills multiple functional needs.

Ability to cooperate $(\alpha=0.79)$

1. This product communicates with other devices.

2. This product achieves a common goal in cooperation with other products.

3. This product can be attached to other products.

4. This product works better in cooperation with other products.

${ }^{\mathrm{a}}$ All items were scored on seven-point scales $(1=$ totally disagree; $7=$ totally agree $)$.

Table A2. Mean Scores ${ }^{a}$ of the Different Levels for the Products of Combination A

\begin{tabular}{|c|c|c|c|c|c|c|}
\hline & \multicolumn{2}{|c|}{ Autonomy } & \multicolumn{2}{|c|}{ Adaptability } & \multicolumn{2}{|c|}{ Reactivity } \\
\hline & Level 1 & Level 2 & Level 1 & Level 2 & Level 1 & Level 2 \\
\hline Vacuum Cleaner & 3.70 & 6.05 & 2.41 & 6.04 & 1.76 & 4.51 \\
\hline Lawn Mower & 3.96 & 5.90 & 2.45 & 6.34 & 2.25 & 4.44 \\
\hline Washing Machine & 3.66 & 5.70 & 1.59 & 6.16 & 1.94 & 3.73 \\
\hline
\end{tabular}

${ }^{\text {a }}$ Post-hoc Scheffé tests indicated that within each dimension the scores for the different levels differed significantly at the $p<.05$ level.

Table A3. Mean Scores ${ }^{\mathrm{a}}$ of the Different Levels for the Products of Combination B

\begin{tabular}{lcccrr}
\hline & Level 1 & $\begin{array}{c}\text { Multifunctionality } \\
\text { Level 2 }\end{array}$ & Level 3 & Level 1 & $\begin{array}{c}\text { Ability to Cooperate } \\
\text { Level 2 }\end{array}$ \\
\hline Refrigerator & 2.48 & 4.63 & 5.67 & 2.76 & 4.75 \\
Digital Camera & 2.89 & 5.15 & 6.01 & 2.97 & 5.49 \\
Washing Machine & 3.05 & 4.06 & 4.82 & 1.67 & 5.97 \\
\hline
\end{tabular}

\footnotetext{
${ }^{\text {a }}$ Post-hoc Scheffé tests indicated that within each dimension the scores for the different levels differed significantly at the $p<.05$ level.
} 